\title{
http:// bjas.bu.edu.eg \\ Evaluation of Platelet Rich Plasma in the Management of Psoriasis
} S.H.Abd-El Rahman ${ }^{1}$, R.M.Salem ${ }^{2}$ and A.H.Ahmed ${ }^{3}$

${ }^{1}$ Assistant Professor of Dermatology,Venereology and Andrology Dept., Faculty of Medicine, Benha Univ., Benha, Egypt

${ }^{2}$ Lecturer of Dermatology,Venereology and Andrology Dept., Faculty of Medicine, Benha Univ.,Benha, Egypt ${ }^{3}$ Resident of Dermatology, Venereology and Andrology Dept., Faculty of Medicineone Day Surgery El Basatine, Egypt E-Mail:waleadmehana@gmail.com

\begin{abstract}
Psoriasis is a chronic immune-mediated disease affecting approximately $2-3 \%$ of general population. It is associated with significant negative impact on patient's physical and psychological quality of life along with vulnerability to co-morbidities such as cardiometabolic dysfunction, depression, and so on [1]. to evaluate the efficiency of platelet rich plasma (PRP) in the management of patients with chronic localized recalcitrant plaque psoriasis. This was a prospective pilot study conducted on 30 cases with chronic localized recalcitrant psoriasis attended Dermatology, Venereology and Andrology outpatient clinics, Benha University Hospitalis. This study was approved by Dermatology, Venereology and Andrology Department and Ethics Commitee in the Faculty of Medicine, Benha University. The study details were discussed with all patients and informed consents were obtained from them before the begining of the study.PASI score had significantly decreased in group I after 8 and 16 weeks of treatment when compared to the baseline $(\mathrm{p}=0.001)$. There was also significant decrease in PASI score between week $8,16(\mathrm{p}=0.0018)$. PASI score showed no significant difference in group II neither at week 8 nor 16 compared to baseline $(\mathrm{p}=0.894)$.
\end{abstract}

\section{Introduction}

Distinctive restorative modalities done psoraisis for example, MTX, cyclosporine, acetretin What's more phototherapy bring fizzled on enhance clinical reaction to such patients. Living therapies focusing on particular parts for safe framework are asound experimental headway again universal immunosuppressant. By cosset factor,such therapies camwood expansion those danger of Creating harm Furthermore predispose patients will entrepreneurial infections including tuberculosis. Should go around unfriendly impacts of systemic therapies Also oversee case for psoriasis that would clinched alongside enough controlled Toward universal systemic therapies, a novel without danger hazard medication modality utilizing PRP through intra-lesional course might have been attempted [2]. This study might have been directed on 30 patients introduced for Ceaseless restricted gentle on direct refractory plaque psoriasis. They were subdivided under 2 groups:. Aggregation i might have been approached for PRP one assembly ii might have been treated Toward emollient.

Psoriasis is An incessant immune-mediated infection influencing pretty nearly $2-3 \%$ for all populace. It may be connected with critical negative sway for patient's physical and mental nature for term alongside defenselessness to co-morbidities for example, cardiometabolic dysfunction, depression, et cetera [9]. There will be a Dire need for new medicine strategy, Likewise dependent upon half for patients would not content for present therapies. Despite pathogenesis stays vague [2].

Platelet rich Plasma (PRP) need been An achievement done incitement Also acceleration from claiming delicate tissue recuperating. A few clinical investigations utilizing PRP Likewise An medicine have accounted for guaranteeing outcomes. Platelets discharge mixed drink about Growth factors, which would accepted to copy physiological recuperating methodology through atomic figure kappa b suppression [10]. Atomic variable kappa b that synchronizes aggravation Might a chance to be a urgent arbiter in the pathogenesis of psoriasis. Atomic variable kappa $b$ might go about as An join to dysregulating crosstalk the middle of epidermal keratinocytes Furthermore resistant cells, prompting epidermal hyperplasia. Later antipsoriatic therapies for example, TNF-alpha blocker, glucocorticoids and interleukin-17 blockers target Also smother atomic figure kappa b indicating tr [3].

\section{Aim of the work}

The aim of the present work was to evaluate the efficiency of platelet rich plasma (PRP) in the management of patients with chronic localized recalcitrant plaque psoriasis.

\section{Patients and methods}

This was a prospective pilot study conducted on 30 cases with chronic localized recalcitrant psoriasis attended Dermatology, Venereology and Andrology outpatient clinics, Benha University Hospitalis. This study was approved by Dermatology, Venereology and Andrology Department and Ethics Commitee in the Faculty of Medicine, Benha University. The study details were discussed with all patients and informed consents were obtained from them before the begining of the study.

\subsection{Inclusion criteria}

Patients aged more than 18 years. Stable psoriasis for 6 months. Psoriasis affects $10 \%$ of body surface area (BSA) and PASI score not exceeding 10 at baseline visit.

\subsection{Exclusions criteria}

Patients with other systemic diseases as autoimmune diseases, inflammatory diseases as diabetes, rheumatoid arthritis, and infectious diseases. Patients received topical anti psoriasis treatment 2 weeks or systemic anti psoriasis treatment 2 months before the study begining. Patients with any of exclusion criteria for platelet rich plasma therapy: systemic disorders such 
haematological diseases (coagulopathies), severe cardiovascular disease, infections, immunodepression, therapy with anticoagulants, anti-aggregants, antiinflammatory drugs in the 5 days before blood donation, haemoglobin values of $<11 \mathrm{~g} / \mathrm{dl}$ and platelets values of $<150000 / \mathrm{L}$.

\subsection{Methods}

This study was conducted on 30 patients presented with chronic localized recalcitrant psoriasis plaques. They were subdivided into 2 groups: $\square$ Group 1: This group included 20 patients who were treated with intralesional injection of PRP. $\square$ Group 2: This group included 10 patients who were treated with emollient as acontrol group.

All patients were subjected to the following:

1- History taking: including age, sex, duration, recurrence, family history, previous treatments, and response to previous treatment,
2- History of systemic diseases or allergic diseases.

3- Complete general and dermatological examination.

4- 4. Itching ,Erythema and Scaling were scaled from 0 to 5 according to improvement .

5- Disease severity was assessed according to Psoriasis Area and Severity Index (PASI) [5].

6- Group I was treated with PRP group II was treated by emollient

\section{Results}

\subsection{Demography}

There was insignificant difference between the studied groups regarding sex and age $(\mathrm{p}=0.07$ and 0.665 respectively) Table (1).

Table (1) Demographic data of the studied groups.

\begin{tabular}{|c|c|c|c|c|c|c|c|}
\hline & \multicolumn{2}{|c|}{$\begin{array}{c}\text { Group I } \\
(\mathbf{n}=\mathbf{2 0})\end{array}$} & \multicolumn{2}{|c|}{$\begin{array}{c}\text { Group II } \\
(\mathbf{n}=\mathbf{1 0})\end{array}$} & \multicolumn{3}{|c|}{ test } \\
\hline & No & $\%$ & No & $\%$ & $\mathbf{X} 2$ & & value \\
\hline \multirow{2}{*}{ Sex } & Female & 7 & $35.0 \%$ & 7 & $70.0 \%$ & \multirow{2}{*}{3.281} & \multirow{2}{*}{0.070} \\
\hline & Male & 13 & $65.0 \%$ & 3 & $30.0 \%$ & & \\
\hline \multirow{2}{*}{ Age } & Mean \pm SD & 37.4 & \pm 11.88 & & $.7 \pm 4$ & - & \multirow{2}{*}{0.665} \\
\hline & Range & & -60 & & -60 & 0.437 & \\
\hline
\end{tabular}

$\mathrm{X} 2$ : Chi square test $\mathrm{t}$ : student test $\mathrm{P}<0.05$ is significant

\subsection{Clinical Findings}

There was insignificant difference between the studied groups regarding age of onset, disease duration, body surface area and PASI $0(\mathrm{P}=0.855,0.674,0.840$ and 0.075 respectively) Table (2). Twelve patients only had positive family history of psoriasis

Table (2) clinical data of studied patients

\begin{tabular}{lllll}
\hline \multirow{2}{*}{ Clincal data } & Group I & Group II & \multicolumn{2}{c}{ Independent t test } \\
\cline { 2 - 5 } Age of onset & Mean \pm SD & Mean \pm SD & t & P value \\
\cline { 2 - 5 } Disease duration & $33.5 \pm 7$ & $33 \pm 7$ & -0.184 & 0.855 \\
BSA & $3.93 \pm 1.4$ & $3.7 \pm 1.4$ & -0.424 & 0.674 \\
PASI 0 score & $3.95 \pm 1.9$ & $3.8 \pm 1.9$ & -0.204 & 0.840 \\
\hline
\end{tabular}

BSA: body surface area

PASI score: psoriasis area severity index

$\mathrm{P}>0.05$ insignificant

\subsection{Treatment outcomes}

Safety

No reported side effects in any of the study patients in both groups.

\section{Efficacy}

PASI score had significantly decreased in group I after 8 and 16 weeks of treatment when compared to the baseline ( $\mathrm{p}=0.001)$. There was also significant decrease in PASI score between week 8, 16 ( $\mathrm{p}=0.0018)$. PASI score showed no significant difference in group II neither at week 8 nor 16 compared to baseline $(\mathrm{p}=0.894)$ Table (3) and Fig (1).

\subsection{Percentage of improvement}

Comparison between percentage of improvement according to PASI score in both groups showed statistically significant difference $(\mathrm{p}=0.044)$. Table (4) and Fig $(2,3)$. 
Table (3) Changes in PASI score

\begin{tabular}{lccc}
\hline & Group I & & Group II \\
\cline { 2 - 3 } PASI (Week0) & Mean \pm SD & & Mean \pm SD \\
PASI (Week8) & $8.2 \pm 2.48$ & $5.7 \pm 1.2$ \\
PASI (Week16) & $4.5 \pm 1.2$ & $5.2 \pm 1.2$ \\
P1 & $3.01 \pm 1.58$ & \\
P2 & 0.001 & \\
P3 & 0.001 & 0.195 \\
\hline
\end{tabular}

PASI score: psoriasis area severity index

P1: difference between week 0 and week 8

P2: difference between week 0 and week 16

P3: difference between week 8 and week 16
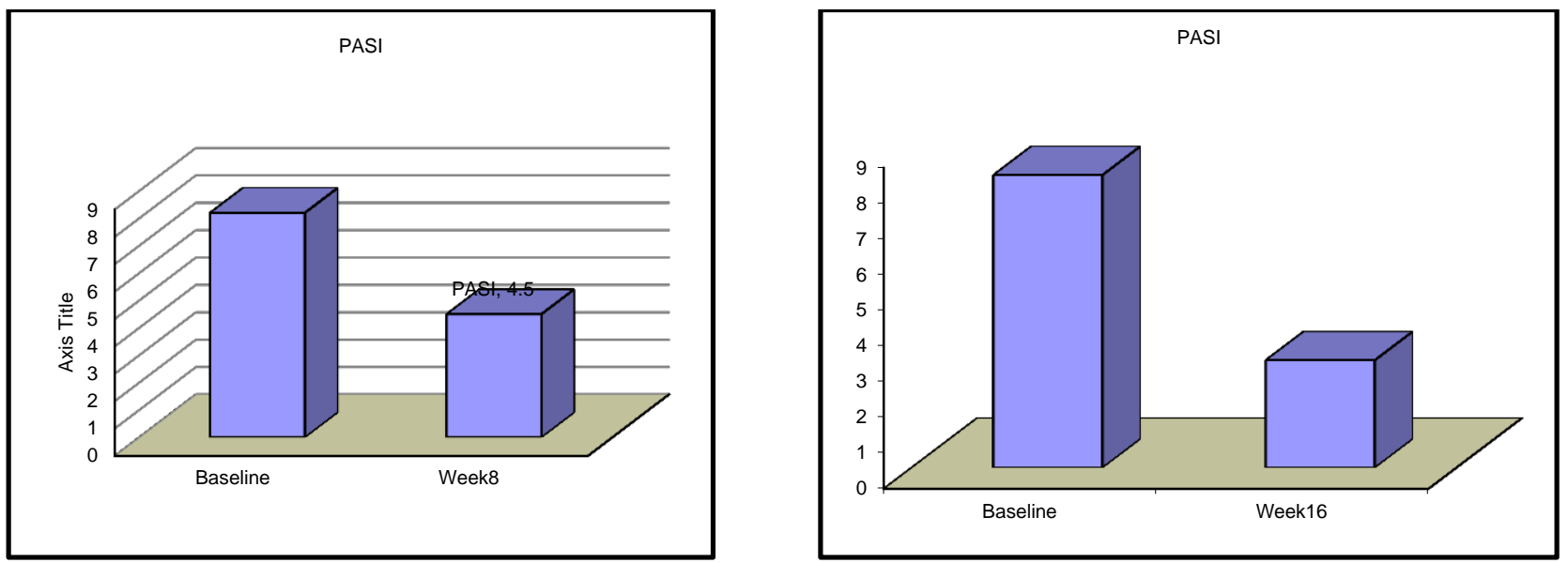

Fig (1) Effect of treatment on PASI score in group I

Table (4) Percentage of improvement in PASI score

\begin{tabular}{lllllll}
\hline & \multicolumn{2}{l}{ group I } & \multicolumn{2}{c}{ group I I } & \multicolumn{2}{c}{ Chi square test } \\
\cline { 2 - 7 } & No & \% & No & \% & X2 & P value \\
\cline { 2 - 7 }$\leq \mathbf{5 0 \%}$ improvement & 8 & 35 & 10 & 100 & 6.429 & 0.044 \\
$\mathbf{7 5 \%}$ improvement & 11 & 45 & 0 & 0 & & \\
$\mathbf{9 0 \%}$ improvement & 1 & 20 & 0 & 0 & & \\
\hline
\end{tabular}

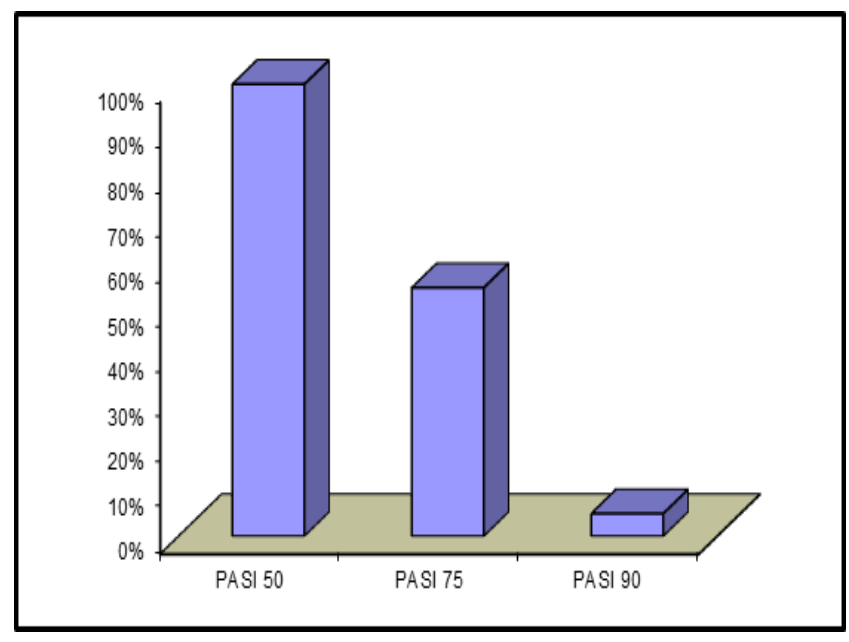

Fig (2) percentage of PASI score improvement in group.

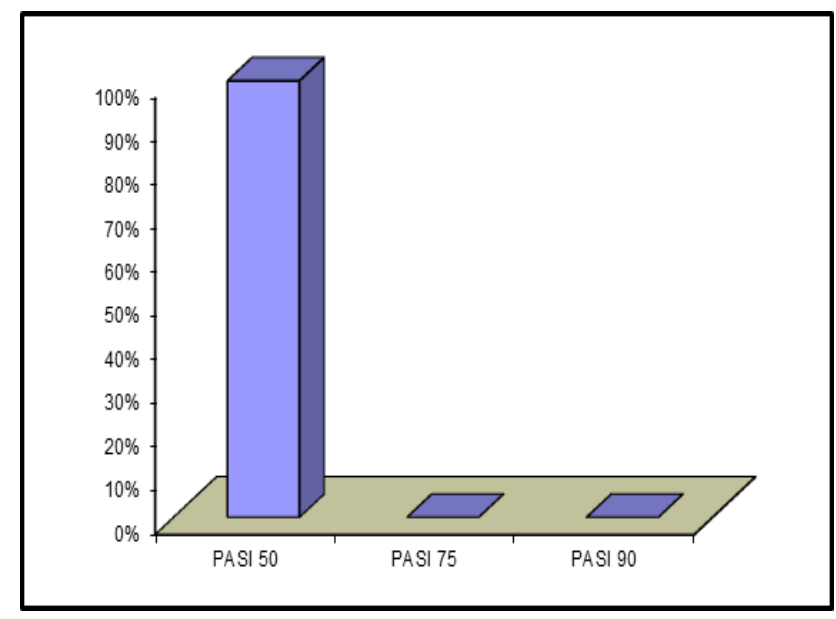

Fig (3) Effect of treatment on PASI score in n group II 
4.5 Clinical data before and after treatment in both groups

There was highly statistically significant difference $(\mathrm{P}=0.001)$ in the mean of improvement of itching, erythema and scaling before and after injection of PRP.In group II there was statistically significant difference in the mean of improvement in itching $(\mathrm{P}=0.001)$ and scaling $(\mathrm{P}=0.001)$ on the other hand erythema showed no significantly improvement $(\mathrm{p}=0.063)$ Table (5).

Table (5) Clinical data before and after treatment in both group

\begin{tabular}{lcccccc}
\hline & \multicolumn{2}{c}{ Itching } & \multicolumn{2}{c}{ Erythema } & \multicolumn{2}{c}{ Scaling } \\
\cline { 2 - 7 } & Before & After & Before & After & Before & After \\
\hline Group I & $4.30 \pm 0.56$ & $2.70 \pm 0.47$ & $4.15 \pm 0.67$ & $2.20 \pm 0.70$ & $4.40 \pm 0.68$ & $2.10 \pm 0.72$ \\
Mean \pm SD & & & & & & \\
Group II & $3.4 \pm 0.24$ & $2.4 \pm 0.14$ & $4.2 \pm 1.24$ & $5.0 \pm 1.4$ & $4.5 \pm 1.23$ & $3 \pm 0.24$ \\
Mean \pm SD & & & & & & \\
P1 & 0.001 & 0.001 & 0.001 \\
P2 & 0.001 & 0.063 & 0.001 \\
P3 & 0.040 & 0.001 & 0.001 \\
\hline
\end{tabular}

P-value $\leq 0.001$ highly significant

P1: difference between before and after treatment in in group I

P2: difference between before and after treatment in in group II P3: difference between group I and group II

Patients of group I were significantly more satisfied with their treatment outcome than patient of groupII $(\mathrm{p}=0.034)$ Table (6).

Table (6) Patient satisfaction in both groups.

\begin{tabular}{lcccccc}
\hline & \multicolumn{2}{c}{$\begin{array}{c}\text { Patient satisfaction } \\
\text { Group I }\end{array}$} & $\begin{array}{c}\text { Patient satisfaction } \\
\text { Group II }\end{array}$ & \multicolumn{2}{c}{ Chi square test } \\
\cline { 2 - 7 } & No & \% & No & \% & X2 & P value \\
\hline Very satisfied & 14 & $70.0 \%$ & 2 & $20.0 \%$ & 8.625 & 0.034 \\
Moderately satisfied & 2 & $10.0 \%$ & 2 & $20.0 \%$ & & \\
Rather not satisfied & 1 & $5.0 \%$ & 4 & $40.0 \%$ & & \\
Very dissatisfied & 3 & $15.0 \%$ & 2 & $20.0 \%$ & & \\
Total & 20 & 100 & 10 & 100 & & \\
\hline
\end{tabular}

Physician were significantly more satisfied with the result of group I than with the result of groupII $(\mathrm{p}=0.042)$ Table $(7)$.

Table (7) Physician satisfaction in both groups

\begin{tabular}{lcccccr}
\hline & \multicolumn{2}{c}{$\begin{array}{c}\text { Physician satisfaction } \\
\text { Group I }\end{array}$} & $\begin{array}{c}\text { Physician satisfaction } \\
\text { Group II }\end{array}$ & \multicolumn{2}{c}{ Chi square test } \\
\cline { 2 - 7 } & No & \% & No & \% & X2 & P value \\
\hline $\begin{array}{l}\text { Very satisfied } \\
\begin{array}{l}\text { Moderately } \\
\text { satisfied }\end{array}\end{array}$ & 15 & $75.0 \%$ & 3 & $30.0 \%$ & & \\
$\begin{array}{l}\text { Rather not } \\
\text { satisfied }\end{array}$ & 3 & $15.0 \%$ & 3 & $30.0 \%$ & & \\
$\begin{array}{l}\text { Very } \\
\text { dissatisfied }\end{array}$ & 2 & $10.0 \%$ & 2 & $20.0 \%$ & 7.500 & 0.042 \\
Total & 0 & $0.0 \%$ & 2 & $20.0 \%$ & & \\
\hline
\end{tabular}

\section{Conclusion}

From the result of this study we can concluded that: Platelet Rich Plasma (PRP) therapy represents a promising new therapeutic option for the patients with chronic localized recalcitrant psoriasis Plaques. The ability to use PRP could resolve several problems occuring with other treatment modalities of psoriasis.

\section{Discussion}

In the current study, patients dealt with with PRP (group I) indicated noteworthy clinical change as communicated by those huge decrease clinched alongside PASI score at the 8th and sixteenth weeks The point when contrasted with the benchmark PASI score. In the sixteenth week, $40 \%$ of the patients for gathering $\mathrm{i}$ attained PASI 50, 55\% attained PASI 75 and 5\% attained PASI 90. 
There might have been special case study who utilized PRP clinched alongside joined with methotrexate. In this ponder 20 patients accepted PRP Likewise a combinational modality with MTX. They separated their patients under two aggregations. Those primary one assembly accepted a joined together help (PRP Also methotrexate) and the other gathering accept methotrexate main $\mathrm{PRP}(\mathrm{ml})$ which might have been injected intralesional as stated by BSA. PASI score Also unfriendly occasions were recorded toward weeks $0,4,8$, 12 What's more 16 [4].

Their outcome demonstrated those rate of change clinched alongside PASI might have been comparative on our contemplate Concerning illustration toward week 16 , all patients in the combinational treatment assembly attained $50 \%$ improvement, 10 out for $16(62.5 \%)$ attained $75 \%$ change and 2 crazy for $16(12.5 \%)$ arrived at $90 \%$ change. Consolidation medicine from claiming PRP for MTX might have been great tolerated by the sum patients without At whatever not kidding unfriendly occasions.

The present outcomes were tantamount to the effects of the combinational bunch clinched alongside, however, PRP monotherapy in the introduce consider attained superior clinical reaction over methotrexate monotherapy over Chakravdhanula. (2016) consider. This error might be in light in the past consider they selected patients for extreme psoraisis directing, including more than $10 \%$ for figure surface zone (BSA) and PASI more than 10 [4].

Bendinelli. (2010) expressed that behind the mitigating part of PRP it Additionally exerts inhibitory impact ahead NF-kB. Besides armstrong. 2017 stated that atomic figure kappa $b$ synchronizes aggravation Might a chance to be a significant arbiter in the pathogenesis for psoriasis. Concerning illustration it might go about as a join clinched alongside dysregulating crosstalk the middle of epidermal keratinocytes Furthermore safe cells, prompting epidermal hyperplasia. This is the reason a few antipsoriatic therapies for example, such that TNF-alpha blocker, glucocorticoids What's more interleukin-17 blockers target and smother atomic component kappa b indicating. PRP likewise lessens chemotaxis Toward hindering chemokine transactivation What's more CXCR4-receptor expression, Subsequently conceivably controlling neighborhood aggravation [7].

Our outcomes were exceptionally near [8]. 31 psoriasis patients were selected Also accepted person single session of intradermal BCG immunization for a measurements of $0.1 \mathrm{ml}$ over the deltoid muscle. Effects demonstrated that PASI score might have been huge decreased then afterward those initial three months. This change is Since BCG immunization might polarize safe framework at a th 1 similar to state. BCG immunization prompted A large number side impacts during infusion webpage including erythema, desquamation and invasion.

Emollients, moisturizers, Furthermore keratolytic operators would key in the topical anesthesia medicine of psoriasis. They help to decrease those scale load for singular patients. The major part for emollients Furthermore moisturizers is the strong part to normalizing hyperproliferation, differentiation, Also apoptosis. Moisturizing results What's more emollients are particularly suitableness in the middle of the road stage Also chronic/remission stage of psoriasis [6].

\section{References}

[1] A. Armstrong , P. Michael , B. Jerry , From the Medical Board of the National Psoriasis Foundation: Treatment Targets for Plaque Psoriasis." JAAD, vol 76 (2), PP 290-9, 2017.

[2] A Brezinski, A Elizabeth, A Jaskaran , W April, Economic Burden of Psoriasis in the United States: A Systematic Review." JAMA dermatology, vol 151 (6), PP 651-58, 2015.

[3] N Catherine, W Melvin, "Psoriasis and Comorbidities: Links and Risks." Clinical, cosmetic and investigational dermatology, PP7: 11, 2014 .

[4] U. Chakravdhanula , K .Anbarasu , V. Verma \& S. Beevi . Clinical efficacy of platelet rich plasma in combination with methotrexate in chronic plaque psoriatic patients, vol . 29,PP 44645, 2016 .

[5] T. Fredriksson. and U Pettersson Severe psoriasis oral therapy with a new retinoid. Dermatologica, Vol. 157,PP 238-24, 1978.

[6] A. Fluhr, W. Joachim, C. Claudia and E. Berardesca. .'Emollients, moisturizers, and keratolytic agents in psoriasis', Clin in dermatology, vol 26, pp380-86, 2008.

[7] G .David, E Sheiner, M Hallak and A LevyPregnancy outcome in women with psoriasis. J Reprod Med, Vol.53(3), PP.183-187.2008

[8] A. Lehrer, A. Bressanelli, VWachsmannImmunotherapy with Mycobacterium vaccae in the treatment of psoriasis :FEMS Immunology \& Medical Microbiology, Vol.21, PP.71 -77 1998.

[9] N. Liu, J. Yan and A .Zheng The relapse of psoriasis treated with topical glucocorticoiSd associated with natural immune memory-like cell activated. JJJoID, Vol.137(5), PP.S99. 2017.

[10] S.E. Mahoney, B.S. Baker, O. Bottasso and M .Bay Triggering psoriasis, the role of infections and medication. Clin Dermatol, PP.25:606-615.2006 . 